\title{
O MOVIMENTO PELA JUSTIÇA GLOBAL NA ESPANHA: ativistas, identidade e cartografia política da alterglobalização*
}

\section{Benjamín Tejerina, Iñaki Martínez de Albeniz, Beatriz Cavia, Andrés G. Seguell, Amaia Izaola**}

\begin{abstract}
Resumo: A rápida expansão dos processos de globalização das últimas décadas facilitou tanto a emergência de formas de resistência em relação com as suas conseqüências como o nascimento de processos de mobilização social a favor de uma globalização alternativa. O trabalho que apresentamos sintetiza parte dos resultados de uma pesquisa sobre o movimento por uma justiça global na Espanha. Nele abordamos a sua base material, as características dos ativistas, a sua identidade política, as suas motivações e interesses e a identidade atribuída à ação do movimento, além de expor a cartografia política que as valorações dos ativistas antiglobalização vêm desenhando. O nosso objetivo é diferenciar analiticamente as coordenadas nas quais se inscreve essa nova forma de subjetividade, cujo espaço social se articula em redor de três eixos: o eixo espacial (dentro-fora, inclusão-exclusão, centroperiferia), o eixo relacional (acima-abaixo, imposição-oposição, repressão-liberação) e o eixo das práticas executadas pelos distintos agentes participantes.
\end{abstract}

Palavras-chave: movimentos sociais, ação coletiva, identidade política, resistência à globalização

\footnotetext{
* Versão preliminar deste trabalho foi apresentada no XXV Congresso da Associação Latino-Americana de Sociologia (ALAS), realizado em Porto Alegre, em agosto de 2005.

** Centro de Estudios sobre la Identidad Colectiva, Departamento de Sociología 2, Facultad de Ciencias Sociales y de la Comunicación, Universidad del País Vasco Euskal Herriko Unibertsitatea. Correo de contacto: b.tejerina@ehu.es
} 


\section{Introdução}

Há mais de uma década que assistimos ao incremento de um gênero de mobilização que apenas se tinha manifestado anteriormente em torno de acontecimentos de grande relevância social. Este tipo de protesto adquiriu visibilidade planetária em Seattle, em novembro de 1999, graças ao impacto social das imagens dos manifestantes contra a Conferência da Organização Mundial de Comércio transmitidas pelos meios de comunicação. Esta não foi a primeira mobilização contra um dos organismos que melhor representa a globalização econômica, nem foi a mais importante em termos de capacidade mobilizadora ou impacto social; no entanto, foi então que um tipo de descontentamento e resistência, expandido geograficamente de maneira desigual, adquiriu visibilidade pública e impacto na consciência de uma sociedade em vias de internacionalização.

Não é a sua relativa novidade que se reveste de interesse para nós, mas sim a rápida expansão desta modalidade de protesto e a sua significação (Della Porta \& Tarrow, 2005). Para que se compreenda o significado social do que se definiu como "movimento de movimentos", propomo-nos responder três questões que consideramos chave.

Em primeiro lugar, vamos abordar a análise das possíveis bases materiais da mobilização. Um dos debates que ocupou o pensamento dos movimentos sociais nos últimos anos está relacionado com as supostas bases estruturais da ação coletiva. Se o movimento operário mergulhava as suas raízes nas estruturas desiguais da propriedade, e a classe social se transformava na base para a sua definição objetiva e estrutura de oportunidade para a pertença subjetiva, os movimentos sociais característicos das décadas de 1980 e 1990 apresentavam-se como realidades interclasses, ou, na maioria dos casos, como um radicalismo de classe média que aspirava opor-se à degradação das condições e da qualidade de vida quotidiana, assim como ao processo de colonização do espaço da privacidade, impulsionando a mobilização dos setores sociais mais afetados por estes processos característicos 
das sociedades de capitalismo tardio. Pretendemos responder à pergunta: quem são os ativistas que, provenientes de vários setores, se encontram no movimento a favor de uma justiça global e quais são as suas características?

Em segundo lugar, interessa-nos saber se há compatibilidade ou incompatibilidade entre os diversos níveis de identificação, setorial/ global, particular/geral, ou se, pelo contrário, são como compartimentos estanques, sem nenhuma relação entre si. Convém recordar que enquanto que o movimento operário e os movimentos sociais e históricos se debruçavam sobre os aspectos da existência social, como a exploração no trabalho, as relações de domínio entre pessoas de diferente gênero, sexo, condição étnica, residência, cultura ameaçada e também sobre aspectos mais gerais, nomeadamente, a defesa do meio ambiente ou a paz, o movimento contra a globalização neoliberal apresenta uma diversidade interna tão ampla que gera crescentes problemas na gestão da sua realidade reivindicativa caleidoscópica.

A identidade, com os seus componentes intencionais, cognitivos e afetivos, assim como os objetivos mais imediatos, pode-nos indicar os territórios pelos quais transitam os processos reticulares de solidariedade, de negociação e de construção das novas fronteiras da mobilização.

Em terceiro lugar, vamos abordar o que poderíamos chamar de processo de construção do global e da alterglobalização. Como é que se define o global e como é que se concretiza a alterglobalização? Para isso, tentaremos delinear uma possível concepção do mundo, que ultrapasse a pluralidade de culturas políticas presentes entre os ativistas do Movimento pela Justiça Global (MJG).

Cada uma das partes deste artigo estará dedicada a responder a estas três perguntas. A informação que apresentamos tem a sua origem num questionário, ao qual responderam 166 ativistas ${ }^{1}$ e cujo trabalho de campo foi efetuado durante os meses de primavera do ano 2004. O mesmo questionário foi realizado noutros países europeus e, posteriormente, vai nos permitir comparar as respostas para 
analisar as diferenças e as semelhanças. Além disso, durante os meses de janeiro e fevereiro de 2005, foram efetuadas 25 entrevistas a ativistas de diferentes organizações, associações e coletivos que consideram fazer parte do MJG, com o intuito de ampliar aspectos referentes à identidade, à cultura política e à proposta alternativa do movimento.

\section{Os ativistas do Movimento pela Justiça Global}

Em alguns movimentos sociais a fonte fundamental de recrutamento coincide com uma categoria social: ocupação, etnia, gênero, idade, local de residência, etc. Precisamente estas categorias sociais, que os cientistas sociais utilizam nos seus questionários como variáveis independentes, converteram-se em elementos significantes e objeto de reivindicação. Apesar de muitos movimentos sociais recrutarem uma grande parte dos seus ativistas de categorias concretas, encontramos indivíduos que não provêm dessas categorias e, por outro lado, nem todos os indivíduos que pertencem a determinadas categorias se tornam ativistas.

Para Claus Offe, as características

do núcleo de ativistas e simpatizantes dos novos movimentos sociais provenientes da nova classe média, incluem um alto nível de formação, uma segurança econômica relativa e emprego no sector de serviços pessoais [...]. É, no entanto, também certo na maioria dos casos que os novos movimentos sociais não se compõem exclusivamente de 'radicais da classe média'; aqueles contam, também, com elementos de outros grupos e camadas, com os quais tendem a criar uma aliança mais ou menos estável. Entre aqueles outros grupos, os mais importantes são: a) os grupos 'periféricos' ou 'desmercantilizados' (donas de casa de classe média, estudantes de ensino secundário e universitários, reformados e jovens no desemprego total ou parcial); b) elementos da velha classe média (independentes e autoempregados como camponeses, lojistas e artesãos). (Offe, 1988, p. 195-196).

Ronald Inglehart (1991, p. 421) sugeriu a tese de que o surgimento dos novos movimentos sociais deve muito ao que se 
denomina mobilização cognitiva, isto é, "ao aumento gradual do nível de habilidade política da população, o que por sua vez se deve a que a educação se tenha difundido mais e a informação política se tenha intensificado".

A idéia de mobilização cognitiva de Inglehart parece coincidir mais com a eclosão dos movimentos sociais, enquanto que o perfil descrito por Offe refere-se às características dos mobilizados. No nosso caso, o alto nível de formação definiria a maioria dos ativistas e, além disso, os mais velhos, que estão representados por um número de casos mais reduzido, viram-se expostos a uma intensificação da informação política durante o período de transição para a democracia em Espanha e nos anos posteriores (1975-1982).

Interessamo-nos por conhecer tanto as características sociodemográficas como as de pertença dos ativistas alterglobalização entrevistados. Entre as primeiras, ficou manifesto que os novos movimentos sociais respondem a um novo "radicalismo das classes médias". A origem deste radicalismo teria a sua base no fato de que os processos de mudança estrutural teriam contribuído, de diversas maneiras, para o enfraquecimento da base dos conflitos sociais tradicionais (Eder, 1993). Juntamente com estas transformações, assistiríamos à emergência de grupos sociais que se destacariam por terem níveis de instrução e por ocuparem uma posição social diferentes dos da classe média tradicional (Della Porta \& Diani, 19997, p. 65). Estas novas classes médias seriam o vínculo entre a mudança estrutural e os novos conflitos sociais. Entre as características sociodemográficas dos ativistas alterglobalização entrevistados podemos manifestar a sua juventude, 72,3\% têm menos de 34 anos e apenas 9\% têm mais de 45 anos (Tabela 1); com habilitações de nível elevado, superior ao nível médio da população, 70,5\% de universitários (Tabela 2); e um grande nível de utilização das novas tecnologias da informação e da comunicação, 60,8\% utilizam o computador todos os dias, $47 \%$ a Internet e $51,8 \%$ o correio eletrônico (Tabela 3). Não existem diferenças de gênero significativas na nossa amostra de entrevistados, ainda que haja uma ligeira maioria de indivíduos do sexo masculino. 
Tabela 1 - Idade dos entrevistados

\begin{tabular}{l||c|c}
\hline \multicolumn{1}{c||}{ Idade } & Abs. & \% \\
\hline \hline $18-34$ anos & 120 & 72,3 \\
\hline $35-45$ anos & 31 & 18,7 \\
\hline Mais de 45 & 15 & 9,0 \\
\hline \hline Total & 166 & 100,0 \\
\hline
\end{tabular}

\section{Tabela 2 - Habilitações dos entrevistados}

\begin{tabular}{l||r|r}
\hline \multicolumn{1}{c||}{ Escolaridade } & Abs. & \multicolumn{1}{c}{$\%$} \\
\hline \hline Nenhuma, primária & 3 & 1,8 \\
\hline Secundária & 39 & 23,5 \\
\hline Universitária & 117 & 70,5 \\
\hline NS/NR & 7 & 4,2 \\
\hline \hline Total & 166 & 100,0 \\
\hline
\end{tabular}

\section{Tabela 3 - Utilização do computador, Internet e correio eletrônico}

\begin{tabular}{l||r|r||r|r||r|r}
\hline \multicolumn{1}{c||}{} & \multicolumn{2}{|c||}{$\begin{array}{c}\text { Utilização do } \\
\text { computador }\end{array}$} & \multicolumn{2}{c||}{ Utilização da Internet } & \multicolumn{2}{c}{$\begin{array}{c}\text { Utilização do correio } \\
\text { electrónico }\end{array}$} \\
\cline { 2 - 7 } & \multicolumn{1}{c||}{ Abs. } & \multicolumn{1}{c||}{$\%$} & Abs. & $\%$ & Abs. & $\%$ \\
\hline \hline Todos os dias & 101 & 60,8 & 78 & 47,0 & 86 & 51,8 \\
\hline Freqüentemente & 42 & 25,3 & 47 & 28,3 & 43 & 25,9 \\
\hline De vez em quando & 12 & 7,2 & 28 & 16,9 & 23 & 13,9 \\
\hline Nunca & 4 & 2,4 & 4 & 2,4 & 5 & 3,0 \\
\hline NS/ NR & 7 & 4,2 & 9 & 5,4 & 9 & 5,4 \\
\hline \hline Total & 166 & 100,0 & 166 & 100,0 & 166 & 100,0 \\
\hline
\end{tabular}

Os ativistas entrevistados desempenham ocupações distintas, destacando-se os que ainda estão estudando $(30,1 \%)$, os que realizam tarefas de caráter intelectual ou relacionadas com a área científica $(18,7 \%)$, trabalhos de escritório $(8,4 \%)$, profissionais de apoio $(7,8 \%)$ 
e, em menor escala, diretivos, funcionários, atividades comerciais e do setor dos serviços, bolsistas, jornalistas, professores, sindicalistas e $7,8 \%$ de desempregados (Tabela 4). Os que estão empregados revelam um índice de precariedade laboral menor $(22,9 \%)$ que o existente no conjunto da população ocupada (33\% em 2005).

\section{Tabela 4 - Profissão e tipo de emprego dos ativistas entrevistados}

\begin{tabular}{l||r|r}
\hline \multicolumn{1}{c||}{ Profissão atual } & Abs. & \multicolumn{1}{c}{$\%$} \\
\hline \hline Diretivo-funcionário & 4 & 2,4 \\
\hline Cientista-intelectual & 31 & 18,7 \\
\hline Apoio profissional & 13 & 7,8 \\
\hline Escritório & 6 & 8,4 \\
\hline Serviços-Comércio & 2 & 3,6 \\
\hline Manufaturas-Construção & 1 & 1,2 \\
\hline Operador-Montador & 6 & 3,6 \\
\hline Trabalho não qualificado & 50 & 30,1 \\
\hline Estudante & 13 & 7,8 \\
\hline Desempregado & 20 & 12,0 \\
\hline Outros & 6 & 3,6 \\
\hline NS/ NR & 166 & 100,0 \\
\hline \hline Total & &
\end{tabular}

Entre os traços relativos à pertença dos entrevistados, uma característica que se destaca em relação às outras é o alto nível de mobilização, uma vez que 90,4\% participam em alguma organização social ou política (Tabela 5).

Tabela 5 - Participação em organizações sociopolíticas

\begin{tabular}{l||r|r}
\hline $\begin{array}{c}\text { Participou em organizações } \\
\text { sociopolíticas }\end{array}$ & Abs. & \% \\
\hline \hline Sim & 150 & 90,4 \\
\hline Não & 16 & 9,6 \\
\hline \hline Total & 166 & 100,0 \\
\hline
\end{tabular}


A multimilitância parece ser outro traço relevante entre os entrevistados, com participação em 1,65 organizações por ativista. A maior parte está simultaneamente em vários grupos coletivos. Numa ordem de maior à menor presença, as organizações nas quais se integram são: outros movimentos sociais, organizações voluntárias, partidos políticos, outras associações de caráter social (universitárias, estudantis e culturais) e sindicatos (Tabela 6).

\section{Tabela 6 - Tipo de organização em que se integram os entrevistados}

\begin{tabular}{l|c|c}
\hline \multicolumn{1}{c||}{ Tipo de organização } & Abs. & \% \\
\hline \hline Partidos políticos & 26 & 17,3 \\
\hline Sindicatos & 18 & 12,0 \\
\hline Movimentos Sociais & 79 & 52,7 \\
\hline Associações & 26 & 17,3 \\
\hline Organizações voluntárias & 46 & 30,7 \\
\hline Outros & 15 & 10,0 \\
\hline NS/ NR & 38 & 25,3 \\
\hline \hline Total & $248^{*}$ & 100,0 \\
\hline
\end{tabular}

* O total não dá 150 porque é resposta múltipla.

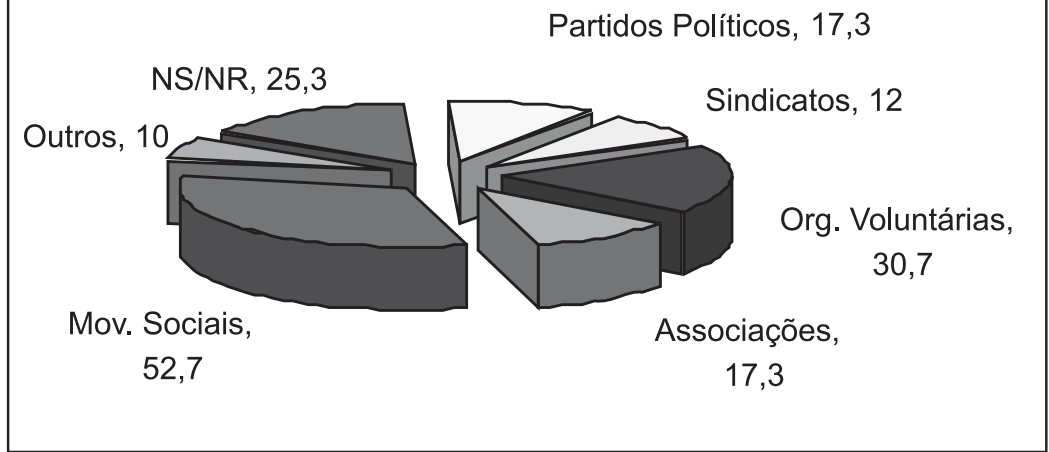

Gráfico 1 - Tipo de organização em que se integram os entrevistados 
Em relação ao tempo de permanência na organização, 41,3\% fica menos de dois anos, $32,7 \%$ entre dois e cinco anos, e $24 \%$ mais de cinco anos, o que quer dizer que se está produzindo uma forte renovação ou então que existe um grande nível de rotatividade entre os que estão menos de dois anos na organização (Tabela 7). $\mathrm{O}$ fato de $74 \%$ estar menos de cinco anos parece indiciar uma colaboração limitada no tempo.

\section{Tabela 7 - Tempo de permanência na organização}

\begin{tabular}{l||r|r}
\hline \multicolumn{1}{c||}{ Meses na organização } & Abs. & \multicolumn{1}{c}{ \% } \\
\hline \hline Menos de 1 ano & 23 & 15,3 \\
\hline Entre 1 e 2 anos & 39 & 26,0 \\
\hline Entre 2 e 5 anos & 49 & 32,7 \\
\hline Entre 5 e 10 anos & 23 & 15,3 \\
\hline Mais de 10 anos & 13 & 8,7 \\
\hline NS/ NR & 3 & 2,0 \\
\hline \hline Total & 150 & 100,0 \\
\hline
\end{tabular}

No que diz respeito às funções dos entrevistados na organização, $54 \%$ são colaboradores habituais, $28 \%$ desempenham tarefas de coordenação, 9,3\% tarefas diretivas e 7,3 são colaboradores pontuais (Tabela 8).

\section{Tabela 8 - Tipo de atividade desenvolvida na organização}

\begin{tabular}{l||c|c}
\hline \multicolumn{1}{c||}{ Atividade realizada } & Abs. & \% \\
\hline \hline Diretivas & 14 & 9,3 \\
\hline Coordenação & 42 & 28,0 \\
\hline Colaboração habitual & 81 & 54,0 \\
\hline Colaboração pontual & 11 & 7,3 \\
\hline NS/ NR & 2 & 1,3 \\
\hline \hline Total & 150 & 100,0 \\
\hline
\end{tabular}


A maior parte dos entrevistados autoposiciona-se no espaço ideológico da esquerda: $10,2 \%$ na extrema esquerda, $44 \%$ no espaço imediatamente anterior da escala (2 sobre 7 ), e $29,5 \%$ na esquerda moderada (Tabela 9).

Tabela 9 - Auto-posicionamento ideológico dos ativistas

\begin{tabular}{l||r|r}
\hline \multicolumn{1}{c||}{ Escala ideológica } & Abs. & \multicolumn{1}{c}{$\%$} \\
\hline \hline 1 Extrema esquerda & 17 & 10,2 \\
\hline 2 & 73 & 44,0 \\
\hline 3 & 38 & 22,9 \\
\hline 4 & 11 & 6,6 \\
\hline 5 & 6 & 3,6 \\
\hline 6 & 1 & 0,6 \\
\hline 7 Extrema direita & 1 & 0,6 \\
\hline NS/ NC & 19 & 11,4 \\
\hline \hline Total & 166 & 100,0 \\
\hline \hline
\end{tabular}

Relativamente às suas crenças religiosas, 46,4\% declara-se ateu, 22,3\% agnóstico e 10,2\% indiferente. Como católico ou católico praticante se definem $12 \%$ (Tabela 10).

Tabela 10 - Definição em termos de crenças religiosas

\begin{tabular}{l||r|c}
\hline \multicolumn{1}{c||}{ Crenças religiosas } & Abs. & \% \\
\hline \hline Católico praticante & 5 & 3,0 \\
\hline Católico não praticante & 15 & 9,0 \\
\hline Indiferente & 17 & 10,2 \\
\hline Agnóstico & 3 & 22,3 \\
\hline Ateu & 7 & 46,4 \\
\hline Outra religião & 1 & 0,6 \\
\hline NS/ NR & 14 & 8,4 \\
\hline \hline Total & 166 & 100,0 \\
\hline
\end{tabular}

O posicionamento dos entrevistados situa-se, claramente, no espectro da esquerda não moderada e num terreno distante das crenças religiosas católicas. 
No que concerne à sua identidade política e ao seu sentimento de pertencer a um movimento global, a maioria dos entrevistados afirma que a sua identidade política está nos novos movimentos sociais (pacifismo, ecologismo, feminismo, autônomo ou solidariedade). Em segundo lugar, surgem os que manifestam que a sua identidade política está no movimento operário, e, seguidamente, emerge a pertença a um movimento global (Tabela 11). Os integrados em movimentos históricos (de vizinhos, estudantil), nacionalistas ou religiosos surgem em número reduzido entre os ativistas entrevistados, cerca de $10 \%$ dos casos. Paradoxalmente, a identidade política situada em diversos movimentos sociais parece ser compatível com uma identificação mais abstrata e geral, pois $81,3 \%$ dos entrevistados declaram sentirse parte de um movimento global (Tabela 12).

\section{Tabela 11 - Identidade política dos ativistas entrevistados}

\begin{tabular}{l|r|r}
\hline \multicolumn{1}{c|}{ Identidade política } & Abs. & \multicolumn{1}{c}{$\%$} \\
\hline \hline Movimento operário & 58 & 34,9 \\
\hline Movimentos sociais & 127 & 76,5 \\
\hline Movimentos históricos & 21 & 12,7 \\
\hline Movimentos religiosos & 11 & 6,6 \\
\hline Movimentos nacionalistas & 18 & 10,8 \\
\hline Movimento global & 50 & 30,1 \\
\hline NS/ NR & 3 & 1,8 \\
\hline \hline Total & $288 *$ & 100,0 \\
\hline
\end{tabular}

* O total não dá 166 porque é resposta múltipla.

Tabela 12 - Sentimento de pertencer a um movimento global

\begin{tabular}{l|r|r}
\hline \hline $\begin{array}{c}\text { P. } 10 \text { Sentes que fazes parte de um } \\
\text { movimento global? }\end{array}$ & Abs. & \% \\
\hline Sim & 135 & 81,3 \\
\hline Não & 19 & 11,4 \\
\hline NS/ NR & 12 & 7,2 \\
\hline Total & 166 & 100,0 \\
\hline
\end{tabular}


Este fato é difícil de compreender e de explicar se entendermos a identificação como dispositivo condicionado pelo local de enunciação, pela localização socioestrutural dos atores, e não como um espaço de confronto, de negociação, como campo ou espaço social. O conceito de classe é substituído no pensamento de Bourdieu pelo de espaço social, equacionando-o como elemento conceitual subsidiário daquele (Bourdieu, 1997, p. 48-49). Este espaço social é um campo de forças, cuja necessidade se impõe aos agentes que penetraram nele, e de lutas, entre os agentes que têm meios e fins distintos segundo a sua posição na estrutura do campo de forças. A idéia de espaço social é duplamente pertinente neste caso porque incorpora a proximidade entre distintas posições e, além disso, porque pertencer a um mesmo espaço social pode contribuir para partilhar um mesmo espaço simbólico.

A existência de um grupo depende da mobilização daqueles que se encontram em posições sociais próximas, às quais se associam disposições e interesses concretos. Formulação muito semelhante à constituição dos grupos em conflito de R. Dahrendorf, embora centrada na proximidade, a saber:

Qualquer coisa parecida com uma classe, ou ainda mais geral, com um grupo mobilizado por e para a defesa dos seus interesses, só pode chegar a existir à custa de um trabalho coletivo de construção teórica e prática; mas não todos os agrupamentos sociais são igualmente prováveis, e esse artefato social que é sempre um grupo social, tem maiores possibilidades de existir e de subsistir duradouramente se os agentes que se agrupam para o constituir estiverem já mais próximos no espaço social. Dito de outro modo, o labor simbólico de constituição ou sagração que é necessário para criar um grupo unido (imposição de nomes, de siglas, de signos de adesão, manifestações públicas, etc.) tem mais possibilidades de ser bem sucedido quando os agentes sociais sobre os quais se exerce, estejam mais propensos, devido à sua proximidade no espaço das posições sociais e também das disposições e dos interesses associados a estas posições, a reconhecer-se mutuamente e a reconhecer-se num mesmo projecto (político ou outro). (Bourdieu, 1997, p. 49). 
Como verificamos nesta primeira parte, existe uma grande proximidade entre as posições dos ativistas entrevistados e, além disso, a identificação com espaços e âmbitos setoriais de reivindicação social (a participação em conflitos sociais particulares) é compatível com a identificação com conflitos globais, assim como com a identificação da sua participação nos referidos conflitos como relevante na definição das suas pertenças. Vamos analisar em pormenor os conteúdos desta identidade em processo de formação, identidade particular e global ao mesmo tempo. É esta identidade multiforme uma manifestação da pluralidade interna do movimento alterglobalização ou representa antes a emergência de uma nova forma de entender a convivência entre âmbitos compatíveis entre diversas identidades? Está se configurando uma nova identidade global e, se assim for, em volta de que conteúdos?

\section{A identidade do Movimento pela Justiça Global}

A abordagem dos novos movimentos sociais enfatiza aqueles aspectos dos movimentos sociais que têm a ver com o processo de construção de novas identidades coletivas, mas não estão aprofundando suficientemente no âmbito pessoal da identidade. ${ }^{2} \mathrm{~A}$ tendência geral foi estudar os processos e fatores sociais que determinam a evolução e o impacto dos movimentos sociais. Nesta conjuntura, os processos microssociais passam para segundo plano.

Omi e Winant (1983), numa avaliação do movimento pelos direitos civis nos EUA, assinalaram que, além dos sucessos legislativos ou da extensão da mobilização de massas, o grande sucesso deste movimento deve procurar-se na sua capacidade para criar um novo "sujeito" e para redefinir o significado da identidade racial e da própria raça na sociedade americana.

Entre os diferentes movimentos sociais existe um tratamento desigual da identidade. A centralidade social dos temas que os movimentos sociais problematizam nem sempre é acompanhada pelo mesmo grau de centralidade para os ativistas ou simpatizantes. 
Enquanto que certos movimentos de caráter religioso ou nacionalista podem implicar um elevado nível de compromisso pessoal para alguns dos seus ativistas, para outros pode supor uma identificação passageira ou instrumental. Outros movimentos sociais problematizam aspectos da vida social que se relacionam diretamente à experiência vital pessoal, como no caso do movimento feminista ou do movimento de gays, lesbianas e transexuais. Do ponto de vista das estratégias pessoais, os ativistas de qualquer movimento podem comprometerse em maior ou menor escala com as práticas da sua organização. No entanto, a idéia que pretendemos realçar é que, do ponto de vista do processo de construção da identidade pessoal, as práticas em que intervêm as relações de gênero ou sexuais parecem ter, em geral, uma maior significação social do que aquelas que afetam aspectos como as relações com o meio, a solidariedade para com os desfavorecidos, etc. Com isto não pretendemos afirmar que para qualquer ativista feminista, gay ou lésbica o seu compromisso tenha a mesma identidade. Neste último caso, quer da perspectiva de como vivem a sua militância ou de como experimentam a sua sexualidade, existem importantes diferenças, inclusivamente diferentes formas de definir e de chegar a ser homossexual (Plummer, 1981; Bell \& Weinberg, 1978).

Juntamente com a identidade pessoal, os grupos também proporcionam uma identidade coletiva. Segundo Melucci, a identidade coletiva é um processo que envolve três dimensões inter-relacionadas que podem ser analiticamente separadas: a) formula sistemas de interpretação relativos aos fins, aos meios e ao âmbito da ação; b) ativa relações entre os atores que interagem, se comunicam, se influenciam mutuamente, negociam e tomam decisões; c) realizam inversões emocionais que permitem aos indivíduos reconhecerem-se a si próprios (Melucci, 1988, p. 343; 1989, p. 35).

Uma definição similar é a elaborada por Polleta e Jasper (2001, p. 284):

as ligações cognitivas, morais, e emocionais de um indivíduo com uma comunidade, uma categoria, uma prática ou uma instituição mais 
ampla. É a percepção de um status partilhado ou relação, que pode ser imaginada mais que experimentada directamente e é distinta das identidades pessoais, podendo, no entanto, fazer parte de uma identidade pessoal. Uma identidade coletiva poderá ter sido inicialmente construída por indivíduos extranhos ao grupo (como por exemplo, o caso dos "hispânicos" neste país [EUA]), mas inclusive no caso en que seja imposta, depende da aceitação daqueles a quem é aplicada. As identidades coletivas são expressadas em formas culturais - nomes, narrativas, símbolos, estilos verbais, rituais, vestimenta, etc. - mas nem todas as formas culturais expressam identidades coletivas. As identidades coletivas não implicam o cálculo racional da avaliação das escolhas que o "interesse" aplica. E ao contrário da ideologia, a identidade coletiva é portadora do sentimento positivo para os outros membros do grupo.

Embora concordemos basicamente com a definição tanto de Melucci como de Polleta e Jasper de identidade coletiva, ${ }^{3}$ estabelecemos alguns aspectos distintivos. A "identidade coletiva" é um conceito com o qual nos referimos a um sentimento de pertença partilhado pelos membros de um grupo ou por vários grupos, mediante o qual é interpretada e definida a realidade, orientando as ações dos que partilham do referido sentimento. A identidade coletiva pode cristalizar e objetivar-se, mas está submetida em qualquer altura à possibilidade de mudança e reelaboração. A identidade coletiva não é algo puramente simbólico - que pertence ao mundo dos sinais e das interpretações -, também pertence ao mundo das práticas sociais (Tejerina, 1999b, 2002).

Os grupos sociais não se limitam a definir a sua identidade a partir de determinadas crenças e sentimentos partilhados, também procuram e procedem à sua materialização, no sentido mais físico do termo, mediante a sua vinculação ao que sucede em determinados territórios ou espaços, o que é particularmente ativado por certas categorias ou posições sociais e, inclusivamente, o que sucede em processos de tradução ou deslocações sociais.

O processo de construção e manutenção da identidade coletiva implicaria as seguintes características: 
a) a sua dimensão dinâmica, isto é, o processo constante de criação e reprodução (Taboada-Leonetti, 1981; Kastersztein, 1981; Erikson, 1966; Tajfel, 1974);

b) a existência de um nós, de uma comunidade de indivíduos que partilham de uma pauta cultural comum, um referente comunitário, evita a necessidade de recorrer a instâncias alheias aos seus membros para alcançar o seu reconhecimento social, o que evidencia o caráter simbólico da identidade coletiva (Cohen, 1985, p. 118);

c) o problema da identidade dos grupos deve estabelecer-se desde a consciência ou a representação que os seus membros têm deles próprios ou a representação que um determinado observador pode ter de um grupo concreto, assim como dos processos de identificação nos quais participam os seus membros;

d) aqueles elementos de caráter simbólico capazes de atribuir significação social às ações dos indivíduos, e converter a significação em algo partilhado, constituem o cerne de todo o grupo social, aquilo sobre o que descansa a especificidade de toda a sociedade, o centro simbólico ordenador da ação (Shils, 1961);

e) os atributos comuns nos quais se fundamenta a identidade de um grupo social são convertidos pelos atores sociais em categorias de adscrição e identificação. Através dos atributos comuns, os seus membros se auto-identificam e são identificados por outros. São categorias que têm a particularidade de gerar diferenças em face de outros grupos sociais, estabelecendo limites ou fronteiras entre os grupos. A persistência dos grupos sociais depende da permanência dos referidos limites (Barth, 1976, p. 16).

Os atributos ou os sinais manifestamente comuns, e os valores, crenças e normas que servem para orientar e julgar a atuação dos membros do grupo, constituem os elementos fundamentais sobre os quais se constrói a identidade coletiva. A identidade coletiva não é 
um a priori da ação ou da mobilização; é, em todo o caso, um lugar de chegada, uma concretização provisória e contingente, e é nesse sentido que nos interessa. Para nós, o realmente relevante no movimento alterglobalização é ele estar contribuindo para o desenho de um território de subjetividades, de práticas e de lutas pela definição dos seus limites, dos seus conteúdos e dos seus nervos constitutivos. O que vamos tentar desenvolver nas páginas que se seguem são as linhas transversais desse território, uma cartografia que mostra os caminhos pelos quais transitam os ativistas do movimento.

Já referimos, no final do ponto anterior, que a maioria dos ativistas entrevistados situam a sua identidade política em movimentos sociais particulares, mas, ao mesmo tempo, manifestam uma identificação com um movimento social mais amplo. Vejamos, brevemente, como se vai configurando esta identidade mediante práticas, participação em mobilizações, atribuição de intencionalidade, sentido da solidariedade e objetivos mais importantes a partir da pertença a organizações concretas.

Tabela 13 - Motivações contra a globalização

\begin{tabular}{l||c|c|c|c}
\hline \hline $\begin{array}{c}\boldsymbol{P} .12 \text { Intervenho em ações coletivas contra a } \\
\text { globalização para * }\end{array}$ & $\mathbf{N}^{\text {* }}$ & Média & Desvio típico & $\begin{array}{c}\text { Q.V. } \\
\text { (\%) }\end{array}$ \\
\hline \hline Afirmar princípios morais de igualdade e justiça & 163 & 4,44 & 0,79 & 17,70 \\
\hline Opor-me à dominação econômica & 163 & 4,50 & 0,74 & 16,44 \\
\hline $\begin{array}{l}\text { Defender a minha identidade nacional em face da } \\
\text { identidade cultural global }\end{array}$ & 159 & 2,85 & 1,47 & 51,51 \\
\hline Impulsionar uma globalização diferente & 158 & 3,75 & 1,40 & 37,20 \\
\hline Transformar as estruturas políticas e a democracia & 160 & 4,45 & 0,93 & 20,90 \\
\hline
\end{tabular}

* nível de 1 "não concordo nada" a 5 "concordo totalmente".

O sentido subjetivo que cada ativista outorga à sua participação em ações coletivas alterglobalização é uma primeira dimensão constitutiva da sua identidade (Weber). O sentido que alcança maior acordo (Tabela 13), próximo do concordo totalmente, é "para oporse à dominação econômica" (4,5 pontos e o menor desvio típico). Seguem-lhe em importância "transformar as estruturas políticas e a democracia" (4,45 pontos) e "afirmar princípios morais de igualdade 
e justiça" (4,44 pontos). Numa posição entre concordo bastante e concordo totalmente situa-se "impulsionar uma globalização diferente" ( 3,75 pontos) e mais centrada encontramos "defender a minha identidade nacional face à identidade cultural global" (2,85 pontos). Os ativistas entrevistados posicionam-se, claramente, em volta de um sentido de justiça e igualdade, da resistência ao domínio econômico e do estímulo transformador das estruturas políticas e da democracia. Em relação à "defesa da identidade nacional", a maioria manifestase em desacordo, embora um número reduzido de entrevistados esteja de acordo, sendo o item que revela maior desvio típico e maior coeficiente de dispersão de Pearson ou quociente de variação (Q.V.).

\section{Tabela 14 - Motivações de solidariedade}

\begin{tabular}{l||c|c|c|c}
\hline \hline \multicolumn{1}{c||}{$\begin{array}{c}\text { P.13 Considero importante unir-me a outros } \\
\text { para* }\end{array}$} & $\mathbf{N}^{\mathbf{*}}$ & Média & $\begin{array}{c}\text { Desvio } \\
\text { típico }\end{array}$ & $\begin{array}{c}\text { Q.V. } \\
\text { (\%) }\end{array}$ \\
\hline \hline Partilhar as minhas reivindicações & 166 & 4,24 & 0,90 & 21,13 \\
\hline $\begin{array}{l}\text { Chegar a um entendimento sobre os nossos } \\
\text { interesses comuns }\end{array}$ & 166 & 4,16 & 0,94 & 22,50 \\
\hline $\begin{array}{l}\text { Gerar solidariedade face ao que a globalização nos } \\
\text { impõe }\end{array}$ & 165 & 4,45 & 0,86 & 19,30 \\
\hline Alterar uma realidade social que não me agrada & 161 & 4,66 & 0,70 & 15,00 \\
\hline
\end{tabular}

* nível de 1 "não concordo nada" a 5 "concordo totalmente".

Partilhar estes sentidos em volta de uma identidade coletiva facilita o compromisso, assim como a sua constituição em torno de um sistema de crenças, organizações, rituais, redes e lealdades. Os entrevistados partilham de um amplo espaço de solidariedade (Tabela 14) que se manifesta num acordo muito forte em redor do sentido transformador da realidade social que não lhes agrada (4,66 pontos), construir um sentimento de solidariedade perante o que se considera uma imposição $(4,45)$, partilhar das mesmas reivindicações $(4,24)$ e entender-se em volta de interesses comuns $(4,16)$. Parece que a construção de um espaço social de solidariedade é um território que conta com uma poderosa predisposição para a sua potencial estruturação. 


\section{Tabela 15 - Aspectos mais valorizados do movimento alterglobalização}

\begin{tabular}{l||c|c|c|c}
\hline \hline $\boldsymbol{P} 18$ Considero importante unir-me a outros para & $\mathbf{N}^{\mathbf{0}}$ & Média & $\begin{array}{c}\text { Desvio } \\
\text { típico }\end{array}$ & Q.V. (\%) \\
\hline \hline A pluralidade dos seus componentes & 161 & 4,18 & 0,90 & 21,56 \\
\hline A diversidade ideológica do movimento & 163 & 3,91 & 0,99 & 25,32 \\
\hline O caráter horizontal democrático do movimento & 152 & 4,10 & 0,81 & 19,80 \\
\hline $\begin{array}{l}\text { O fato de se referir a questões quetranspõem as } \\
\text { fronteiras culturais }\end{array}$ & 162 & 4,04 & 0,96 & 23,64 \\
\hline $\begin{array}{l}\text { A possibilidade de alcançar os meus interesses e } \\
\text { compromissos individuais }\end{array}$ & 156 & 2,98 & 1,31 & 44,03 \\
\hline $\begin{array}{l}\text { Servir como porta-voz para as pessoas política e } \\
\text { culturalmente invisíveis }\end{array}$ & 156 & 3,79 & 1,16 & 30,66 \\
\hline
\end{tabular}

* nível de 1 "não concordo nada" a 5 "concordo totalmente"; os NS/NR foram eliminados (valor 6).

A pluralidade interna do movimento alterglobalização pode ser vista como um impedimento para alcançar a necessária unidade com o intuito de agir coletivamente e defender interesses concretos. No entanto, a realidade não é avaliada deste modo pelos entrevistados (Tabela 15), uma vez que a sua composição plural alcança a valorização mais positiva ( 4,18 pontos) entre todas as alternativas de avaliação propostas, seguida do caráter horizontal e democrático do movimento $(4,10)$ e a sua referência a questões transculturais $(4,04)$. A diversidade ideológica (3,91 pontos) e servir de porta-voz de setores sociais política e culturalmente sem visibilidade $(3,79)$ situam-se num segundo grupo de aspectos positivamente valorizados, mas com um grau de intensidade menor que os referidos anteriormente. A utilização do movimento alterglobalização para concretizar interesses e compromissos individuais divide os entrevistados que o valorizam mais e menos em dois grupos quase iguais. É possível que alguns ativistas possam ver a utilização do movimento para conseguir fins de caráter individual como algo ilegítimo (2,98 pontos). 
Tabela 16 - Finalidade do movimento alterglobalização

\begin{tabular}{l||c|c|c|c}
\hline \hline $\begin{array}{c}P .19 \text { O movimento alterglobalização } \\
\text { está } \text { a contribuir para ...* }\end{array}$ & No & Média & $\begin{array}{c}\text { Desvio } \\
\text { típico }\end{array}$ & $\begin{array}{c}\text { Q.V. } \\
\text { (\%) }\end{array}$ \\
\hline \hline Melhorar a democracia & 158 & 3,45 & 1,12 & 32,32 \\
\hline Alterar a perspectiva sobre a globalização & 160 & 4,25 & 0,90 & 21,27 \\
\hline $\begin{array}{l}\text { Consciencializar sobre os riscos da globalização } \\
\text { Que os cidadãos participem socialmente } \\
\text { nos problemas que os afetem }\end{array}$ & 161 & 4,35 & 0,83 & 18,97 \\
\hline \hline
\end{tabular}

* nível de 1 "não concordo nada" a 5 "concordo totalmente"); os NS/NR foram eliminados (valor 6).

As idéias de conscientizar sobre os riscos da globalização $(4,35$ pontos) e de alterar a perspectiva sobre a globalização ( 4,25 pontos) são as afirmações que os entrevistados mais aprovam, no duplo sentido de percepção da eficácia da mobilização e de progressiva expansão da própria consciência (Tabela 16). Mais afastadas destas valorizações encontramos uma grande aprovação da contribuição do movimento para que os cidadãos participem socialmente nos problemas que os afetam $(3,59)$, enquanto capacidade de convicção e mobilização, e a melhorar a democracia $(3,45)$.

\section{Tabela 17 - Interesse em manter relações com outros grupos}

\begin{tabular}{l|c|c|c|c}
\hline \hline $\begin{array}{c}\text { P. 30 Interessa-me a relação com outros grupos } \\
\text { unicamente... * }\end{array}$ & $\mathbf{N}^{\text {0 }}$ & Média & $\begin{array}{c}\text { Desvio } \\
\text { típico }\end{array}$ & $\begin{array}{c}\text { Q.V. } \\
\text { (\%) }\end{array}$ \\
\hline \hline Para construir um movimento o mais amplo possível & 162 & 4,12 & 0,98 & 23,86 \\
\hline Para o protesto, mas não como parte de um esforço comum & 151 & 2,56 & 1,23 & 48,09 \\
\hline $\begin{array}{l}\text { Para nos coordenarmos com os que estão ideologicamente } \\
\text { mais próximos de nós }\end{array}$ & 161 & 3,61 & 1,14 & 31,44 \\
\hline
\end{tabular}

* nível de 1 "não concordo nada" a 5 "concordo totalmente"); os NS/NR foram eliminados (valor 6).

Qual é a finalidade atribuída à colaboração com outros grupos dentro do movimento alterglobalização? O desejo de construir um movimento social amplo alcança o nível de acordo mais elevado $(4,12$ pontos). De acordo com a percepção dos ativistas, a construção de um movimento é a razão do relacionamento (Tabela 17). Também 
com um grande nível de concordância, encontramos que os ativistas se interessam pela coordenação com aqueles que estão mais próximos ideologicamente deles (3,61 pontos), o que pode significar, por sua vez, um desinteresse por se relacionarem com os que se encontram situados noutras coordenadas ideológicas. Entre os entrevistados, $48,8 \%$ não concordam com a idéia de se relacionarem exclusivamente para o protesto, sem fazer parte de um esforço comum, enquanto que apenas 22,9 \% concordam com esta idéia. Não nos é possível determinar se a solidariedade que estas opiniões manifestam se limita à afinidade ideológica ou alcança também outros setores sociais afastados ideologicamente.

Taylor e Whittier (1992) indicaram três ferramentas analíticas para compreender a construção da identidade coletiva: as fronteiras, a consciência e a negociação. Pois, tanto do ponto de vista dos conteúdos ideológicos, da constituição de um sentido de nós diferenciado (fronteiras), da formulação de um sentimento alterglobalizador (consciência), como do estabelecimento de uma ação coletiva partilhada (negociada), as manifestações dos ativistas entrevistados revelam uma clara identidade coletiva, de cujo suporte cultural estrutural nos ocupamos no seguinte ponto. Este suporte cultural estrutural viria a possibilitar a construção de uma cosmovisão, não tanto como algo fechado, redondo e acabado, mas sim como realidade em processo constituinte, uma espécie de cartografia política ${ }^{4}$ que permite aos ativistas habitar o mundo da globalização e transitar para a alterglobalização, deslocar-se de um para o outro e entre ambos.

\section{A cartografia política da alterglobalização}

Segundo a formulação clássica de Almond e Verba, "o termo cultura política refere-se a orientações especificamente políticas, posturas relativas ao sistema político e aos seus diferentes elementos, assim como atitudes em relação ao papel da própria pessoa dentro do referido sistema. Falamos de uma cultura política do mesmo modo 
que poderíamos falar de uma cultura econômica ou religiosa. É um conjunto de orientações em relação a um sistema especial de objetos e processos sociais" (Almond \& Verba, 1965). Esta definição remete para um corpus cultural especificamente político; um conjunto diferenciado e separável de crenças, valores, comportamentos, símbolos, discursos, memórias, expectativas, papéis e maneiras que giram em volta do político. Nela ecoa uma espécie de visão universalista do político que é conseqüência, primeiro, de uma dissociação entre política e cultura, seguida da articulação de um sistema cultural especificamente político que se caracteriza por uma forte identificação universal (transcultural) entre o político e o âmbito de atividade próprio das instituições (Martínez de Albeníz, 2003).

O problema teórico que se coloca ao considerar a cultura política como um caso especial da cultura com $\mathrm{C}$ maiúsculo, é que fica inexplorado o terreno das relações e vinculações entre ambos os âmbitos, o que afeta o conhecimento cabal do seu processo de produção e transmissão. Por outro lado, surge um importante problema empírico, pois detrás das novas culturas políticas nem sempre encontramos setores anti-institucionais ou extra-institucionais, forças anti-sistema, coletivos de desiludidos ou falta de civismo.

A cultura política pode ser considerada desde outra perspectiva. Pode ser entendida como o conjunto de atitudes, opiniões e comportamentos relativos às normas que hão de regular os processos de conflito social que existem na sociedade, os elementos cognitivos, afetivos e práxicos referidos aos agentes que intervêm nos processos de tomada de decisões que afetam a convivência coletiva, e as experiências, práticas sociais e avaliações morais sobre a atribuição de responsabilidade tanto aos atores coletivos como às instituições que intervêm na gestão e planificação do devir de uma sociedade, entre as quais aquelas que concorrem para se tornarem responsáveis pela tomada de decisões no âmbito do Estado e dos regulamentos supra-estatais são um caso.

Com esta definição tentamos ampliar os reduzidos confins nos quais se tem vindo a encaixar numa cultura política entendida como 
cultura política institucionalmente orientada, cultura política de âmbito nacional e cultura política majoritária ou dominante; em todo o caso, seria preferível e sociologicamente mais apropriado falar de cultura política no plural. No entanto, ao distinguir os diferentes componentes da(s) cultura(s) política(s) observamos que este conceito se revela inapropriado para dar conta do que está acontecendo no movimento alterglobalização. Mais do que procurar uma cultura política diferenciada, a pergunta à qual devemos responder é se as orientações e práticas devem considerar-se parte da cultura política dos cidadãos ou se, pelo contrário, ao estudar a cultura política devemos remeternos exclusivamente às opiniões e às atitudes em face dos atores e âmbitos políticos institucionalizados.

Em nossa opinião, a primeira opção fornece elementos fundamentais para a análise e para a compreensão dos processos políticos nas sociedades avançadas, sem cuja consideração estes resultam opacos. Sobretudo, fornece luz aos processos sociais de produção de novas dinâmicas culturais que emergem nos limites da política institucionalizada e concorrem com ela por novas definições, contribuindo para a sua transformação.

Além disso, o global e a alterglobalização constituem um território em disputa, em redefinição e certas formulações dele encontram-se no movimento alterglobalização, pelo que resulta muito insatisfatório qualquer tentativa unidimensional de coisificação. E, ao mesmo tempo, o conceito de cultura política é ainda demasiado homogêneo, demasiado compacto, liso, sem arestas, como para dar conta da pluralidade de tensões que inclui: a) o instituído e o instituinte; b) o político e o cultural; c) o visível e o oculto; e, d) o ter (ser) e o viver (habitar). Falar de uma cartografia política de alterglobalização, em vez de uma cultura política, tem como vantagens: a) representar um guia de tempos, locais e práticas diferentes e diferenciadas; b) permitir entender melhor que práticas similares possam originar percursos e interpretações diversas; e, c) adaptar-se melhor à compreensão de uma realidade que parece um mundo aberto, cheio de hipóteses, mas - ao mesmo tempo - com caminhos muito 
transitados, que agasalha o novo e o velho e, no entanto, é identificável e discernível.

É assim que nós o entendemos e para captar esta realidade fluida e mudável orientou-se a construção do questionário, perguntando aos entrevistados acerca de aqueles aspectos que formam parte relevante da weltanschauung característica das sociedades tecnologicamente orientadas e em processo de crescente globalização. Os cinco âmbitos de nossa atenção são: 1) o contexto do trabalho; 2) os interesses que existem por detrás do conhecimento, da investigação e da formação; 3) os modelos de consumo; 4) as relações de dominação no âmbito da cultura; e, 5) o papel regulador das instituições políticas. Vamos deter-nos a considerar, brevemente, a visão que os ativistas do movimento alterglobalizador manifestam destes cinco âmbitos da sociedade.

Não parece necessário recordar que o trabalho foi, e continua a ser, uma instituição fundamental da sociedade. A maioria das tipologias evolutivas da sociedade faz referência ao caráter do trabalho dominante para definir cada um dos seus tipos ou etapas constitutivos. Nas perguntas que formulamos aos entrevistados incluímos elementos característicos da situação atual do emprego, do seu caráter expressivo, das suas condições, conseqüências e agentes (Tabela 18). O que parece incomodar mais os ativistas é o poder das multinacionais e dos grupos financeiros (4,75 pontos) e as consequiências laborais da globalização (4,64 pontos). Aparece assim, como elemento destacado da avaliação, a desigual distribuição do poder e as conseqüências para uma das partes - os trabalhadores que intervêm na produção global. Esta ênfase ou sensibilidade para com a desigualdade, a escassez de justiça e a oposição à dominação econômica já tinha surgido anteriormente. A falta de emprego $(4,43)$ e as incertezas da vida profissional (flexibilidade, mobilidade, insegurança, precariedade) - 4,11 pontos - surgem seguidamente como aspectos do mundo laboral atual que maior incômodo provocam. A possível falta de expressividade ou a dificuldade para expressar a própria criatividade no trabalho $(3,83$ pontos $)$ e a ausência de 
independência $(3,75)$, ao ter que trabalhar como empregado, geram uma menor incomodidade, embora ainda seja importante.

Tabela 18 - Avaliações sobre o contexto do trabalho

\begin{tabular}{|c|c|c|c|c|}
\hline $\begin{array}{c}\text { P.43 Avalia os seguintes aspectos do mundo } \\
\text { actual* }\end{array}$ & $\mathbf{N}^{\mathbf{0}}$ & Média & $\begin{array}{c}\text { Desvio } \\
\text { tipico }\end{array}$ & $\begin{array}{l}\text { Q.V. } \\
\%\end{array}$ \\
\hline Falta de emprego & 161 & 4,43 & 0,80 & 17,99 \\
\hline Incerteza da vida profissional & 160 & 4,11 & 0,91 & 22,17 \\
\hline Dificuldade para exprimir a própria criatividade & 157 & 3,83 & 1,00 & 25,98 \\
\hline Ter que trabalhar como empregado ou para o mercado & 157 & 3,75 & 1,06 & 28,16 \\
\hline O poder das multinacionais e dos grupos financeiros & 161 & 4,75 & 0,53 & 11,12 \\
\hline Consequências laborais da globalização & 160 & 4,64 & 0,63 & 13,53 \\
\hline
\end{tabular}

* nível de 1 "não me incomoda nada" a 5 "incomoda-me muito".

Referimo-nos com freqüência à sociedade atual como sociedade do conhecimento. Embora o conhecimento não seja um aspecto exclusivo desta época, o papel central da ciência e a criação de processos reflexivos associados aos seus avanços tecnológicos permitiu generalizar o qualificativo de sociedades de ciência (Lamo de Espinosa), da informação (Castells) ou de conhecimento (Stehr). A capacidade de intervenção social sobre a nossa própria natureza alcançou níveis impensáveis há pouco tempo (Melucci), o que expandiu a idéia de que a ciência, conhecimento e sistema educativo - encarregado da sua transmissão - ocupam um lugar central na sociedade atual. Perguntamos aos ativistas sobre o uso e a orientação que deveriam ter a educação, a investigação, a ciência, a tecnologia e o conhecimento em geral. O elemento que provoca maior incômodo é a política de privatização do ensino e da investigação (4,63 pontos), assim como que a ciência e a tecnologia não se orientem a resolver problemas sociais básicos (4,51 pontos). Privatização de certos usos da investigação e orientação para problemas sociais básicos parece situar-se num mesmo contínuo avaliativo, quase uma composição em termos de antagonismo axiológico (Tabela 19). 


\section{Tabela 19 - Avaliações sobre a escola e o conhecimento}

\begin{tabular}{|c|c|c|c|c|}
\hline & $\mathbf{N}^{0}$ & Média & $\begin{array}{c}\text { Desvio } \\
\text { típico }\end{array}$ & $\begin{array}{l}\text { Q.V. } \\
(\%)\end{array}$ \\
\hline $\begin{array}{l}\text { Falta de ligação entre os conhecimentos que se aprendem } \\
\text { no sistema educativo e as necessidades pessoais }\end{array}$ & 160 & 4,11 & 0,95 & 23,16 \\
\hline $\begin{array}{l}\text { Desconexão entre os conhecimentos que se ensinam no } \\
\text { sistema educativo e a inserção profissional }\end{array}$ & 156 & 3,78 & 1,16 & 30,74 \\
\hline $\begin{array}{l}\text { Transmissão de conhecimento ligado exclusivamente ao } \\
\text { sistema de valores dominante }\end{array}$ & 156 & 4,43 & 0,80 & 17,97 \\
\hline $\begin{array}{l}\text { Sistema educativo demasiado ligado às necessidades do } \\
\text { mercado }\end{array}$ & 159 & 4,28 & 0,93 & 21,82 \\
\hline Políticas de privatização do ensino e da investigação & 158 & 4,63 & 0,63 & 13,67 \\
\hline $\begin{array}{l}\text { Sistema educativo demasiado determinado por uma } \\
\text { perspectiva neoliberal }\end{array}$ & 158 & 4,41 & 0,82 & 18,64 \\
\hline Dificuldade no acesso ao conhecimento & 157 & 4,24 & 0,80 & 18,77 \\
\hline $\begin{array}{l}\text { Que a ciência e a tecnologia não se dediquem a resolver } \\
\text { problemas sociais básicos }\end{array}$ & 156 & 4,51 & 0,76 & 16,81 \\
\hline
\end{tabular}

A curta distância situam-se as respostas sobre a transmissão de conhecimento ligado exclusivamente ao sistema de valores dominante, com um nível de rejeição de 4,43 pontos e a existência de um sistema educativo demasiado determinado por uma perspectiva neoliberal $(4,41)$. Valores dominantes e perspectiva neoliberal parecem remeter para o mesmo âmbito de avaliação. Que o sistema educativo se encontre demasiado ligado às necessidades do mercado produz um alto nível de rejeição $(4,28)$, assim como as dificuldades no acesso ao conhecimento $(4,24)$ e a falta de relação entre os conhecimentos que se aprendem no sistema educativo e as necessidades pessoais $(4,11)$. A idéia que origina menor incômodo, mesmo sendo muito relevante, é a desconexão entre os conhecimentos que se ensinam no sistema educativo e a inserção profissional (3,78 pontos). De tudo isto, podemos concluir que se rejeita a privatização da investigação; que a sua prioridade não sejam os problemas sociais básicos; que o mercado, os valores dominantes ou a perspectiva neoliberal orientem a educação e o conhecimento, assim como a falta de democracia no acesso ao conhecimento e a sua desvinculação das necessidades pessoais. 
As drásticas mudanças realizadas nas sociedades industriais implicaram a transformação da estrutura de plausibilidade daquela forma de identidade coletiva que se articulava em torno do mundo do trabalho. Redução da taxa de filiação sindical, diminuição do número de trabalhadores ocupados em certos ramos produtivos, dispersão de enclaves sociais culturalmente homogêneos do ponto de vista da sua densidade de classe, são alguns dos fatores que fizeram com que a mobilização de classe tenha perdido relevância política e a identidade de classe significação social.

As condições sociais de trabalho na sociedade pós-fordista não fazem mais do que limitar o recurso a esta fonte de identidade. Como formulou L. E. Alonso (2000, p. 217), "os ditames do novo espírito do capitalismo dissolvem tanto a profissão - vocação -, como a consciência coletiva das organizações, que ficam diluídas na superfície da sociedade rede". Até o ponto de que este processo pode terminar com o trabalho enquanto fonte de identidade coletiva uma vez que, segundo L. E. Alonso, a sociedade pós-moderna "anunciaria a perda de referências sociais dos sujeitos no lugar de produção (...) e considera o consumo como uma forma de aventura que permite a plasticidade e a expressividade, esquece sempre que nesta situação os sujeitos sociais podem-se desagregar em puros indivíduos encerrados num mundo autista e egoísta plenamente descomprometido e desinteressado do coletivo" (p. 17).

A questão que desejamos colocar a este respeito é se, efetivamente, a sociedade de consumo nos transforma em pessoas tão plásticas, em sujeitos tão autistas e egoístas que nos desinteressamos do coletivo, ou se entre os ativistas alterglobalizadores encontramos traços daquela cultura de trabalho não de todo individualista. A solidariedade está também presente entre os entrevistados, embora tenha adquirido outros significados. A busca de um consumo que não ignore o equilíbrio ecológico (4,68 pontos), o abandono do consumo orientado para a especulação econômica $(4,62)$ e a rejeição do consumo de produtos elaborados em países em vias de desenvolvimento em condições de exploração $(4,58)$, são as avaliações que alcançam um grau mais elevado de irritação (Tabela 20). 
Também surgem outros aspectos relacionados com a desigualdade de acesso ao consumo, tanto entre áreas desenvolvidas e não desenvolvidas $(4,43)$ como, dentro das áreas desenvolvidas, entre distintos sectores sociais $(4,18)$, a utilização instrumental do consumo como símbolo de status $(4,35)$ e a relativa falta de controle sobre aspectos importantes da vida $(4,37)$. Justiça, igualdade, solidariedade, não exploração das pessoas, equilíbrio ecológico e controle social da vida seriam os componentes valorativos constitutivos desta cultura política no que se relaciona com a sociedade de consumo.

Tabela 20 - Avaliações sobre os modelos de consumo

\begin{tabular}{l||c|c|c|c}
\hline & $\mathbf{N}^{\mathbf{0}}$ & Média & $\begin{array}{c}\text { Desvio } \\
\text { típico }\end{array}$ & $\begin{array}{c}\text { Q.V. } \\
\mathbf{( \% )}\end{array}$ \\
\hline \hline $\begin{array}{l}\text { Consumir produtos elaborados em países em vias de } \\
\text { desenvolvimento em condições de exploração }\end{array}$ & 158 & 4,58 & 0,79 & 17,29 \\
\hline Acesso desigual ao consumo em áreas desenvolvidas & 156 & 4,18 & 0,85 & 20,24 \\
\hline $\begin{array}{l}\text { Acesso desigual ao consumo entre áreas } \\
\text { desenvolvidas e não desenvolvidas }\end{array}$ & 156 & 4,43 & 0,79 & 17,79 \\
\hline Consumo de bens como símbolo de status & 156 & 4,35 & 0,82 & 18,80 \\
\hline Consumo dirigido à especulação econômica & 157 & 4,62 & 0,60 & 13,07 \\
\hline Consumo que ignora o equilíbrio ecológico & 157 & 4,68 & 0,59 & 12,59 \\
\hline $\begin{array}{l}\text { Falta de controle sobre aspectos importantes da tua } \\
\text { vida }\end{array}$ & 151 & 4,37 & 0,71 & 16,20 \\
\hline
\end{tabular}

O que é que tem de político a cultura ou o que é que há de cultura política nos modelos culturais e institucionais? É o que colocam as questões das Tabelas 21 e 22. Em relação aos modelos culturais o que mais incomoda os entrevistados é a excessiva concentração do poder por parte do capital (4,71 pontos), partilham também um acentuado sentido da justiça entre mulheres e homens, rejeitando com intensidade a ausência de eqüidade entre os gêneros $(4,69)$. A dominação exercida por aqueles que controlam a informação no âmbito mundial também gera um forte sentimento de incômodo $(4,65)$. Uma vez mais se manifesta uma especial sensibilidade contra aqueles que acumularam uma grande quantidade de poder. Em segundo lugar, surge uma série de itens relativos à repressão de estilos de vida 
alternativos $(4,47)$, a falta de controle social dos indivíduos sobre o modelo de sociedade $(4,35)$, os espaços programados e planificados da vida como a produção cultural industrializada $(4,34)$, a imposição e falta de liberdade individual $(4,27)$ e de reconhecimento da diversidade cultural $(4,36)$, que indicam a existência de uma cultura da resistência e de procura de padrões culturais alternativos àqueles que os entrevistados consideram que se trata de impor a partir de instâncias com mais poder. Nas entrevistas realizadas a ativistas aparecem numerosos exemplos de experiências que tentam construir, ocupar e viver espaços alternativos à margem dos controles do poder econômico, político e cultural.

Tabela 21 - Avaliações sobre os modelos culturais

\begin{tabular}{l||c|c|c|c}
\hline & $\mathbf{N}^{\circ}$ & Média & $\begin{array}{c}\text { Desvio } \\
\text { típico }\end{array}$ & $\begin{array}{c}\text { Q.V. } \\
\mathbf{( \% )}\end{array}$ \\
\hline \hline $\begin{array}{l}\text { Falta de controle dos indivíduos sobre o modelo de } \\
\text { sociedade }\end{array}$ & 154 & 4,35 & 0,75 & 17,33 \\
\hline Repressão de estilos de vida alternativos & 158 & 4,47 & 0,69 & 15,50 \\
\hline Produção cultural planificada pela indústria cultural & 152 & 4,34 & 0,71 & 16,34 \\
\hline $\begin{array}{l}\text { Domínio exercido por aqueles que controlam a } \\
\text { produção da informação aonível mundial }\end{array}$ & 154 & 4,65 & 0,62 & 13,35 \\
\hline Excessiva concentração do poder por parte do capital & 155 & 4,71 & 0,53 & 11,34 \\
\hline Imposição de modelos de liberdade individual & 155 & 4,27 & 0,87 & 20,37 \\
\hline Falta de reconhecimento das diferenças culturais & 157 & 4,36 & 0,73 & 16,63 \\
\hline Ausência de eqüidade entre os gêneros & 156 & 4,69 & 0,49 & 10,45 \\
\hline \hline
\end{tabular}

Não fica claro se a crítica às instituições que aparece nesta cartografia política específica implica um desejo de maior ou menor presença da política. Pensamos que é mais uma crítica por falta ou carência que por excesso, isto é, que se deseja mais política e mais intervenção das instituições políticas e não menos, como reclamaria, por exemplo, uma crítica de posturas neoliberais ou abertamente favoráveis à globalização. De novo, o uso da força e da violência, tanto sob a forma de conflitos bélicos como mediante a utilização do terrorismo, alcança o maior nível de incômodo (4,66 pontos), seguido do poder dos países desenvolvidos $(4,53)$ onde os entrevistados se incluem (Tabela 22). 
Tabela 22 - Avaliações sobre as instituições públicas

\begin{tabular}{l||c|c|c|c}
\hline & $\mathbf{N}^{\mathbf{0}}$ & Média & $\begin{array}{c}\text { Desvio } \\
\text { típico }\end{array}$ & $\begin{array}{c}\text { Q.V. } \\
\mathbf{( \% )}\end{array}$ \\
\hline \hline $\begin{array}{l}\text { Incapacidade das instituições em geral para } \\
\text { enfrentar os efeitos produzidos pela globalização }\end{array}$ & 156 & 4,29 & 0,81 & 18,90 \\
\hline $\begin{array}{l}\text { Poder dos países desenvolvidos } \\
\text { Distanciamento das instituições européias dos } \\
\text { problemas da vida quotidiana }\end{array}$ & 157 & 4,53 & 0,63 & 13,82 \\
\hline $\begin{array}{l}\text { Distanciamento das instituições nacionais dos } \\
\text { problemas individuais e coletivos da vida quotidiana }\end{array}$ & 155 & 4,31 & 0,87 & 20,74 \\
\hline Papel secundário do Estado nas decisões políticas & 151 & 3,96 & 0,96 & 24,19 \\
\hline As guerras e o terrorismo & 151 & 4,66 & 0,60 & 12,90 \\
\hline
\end{tabular}

O distanciamento e a incapacidade de intervenção das instituições políticas constituem um segundo bloco de aspectos importantes - enquanto crítica e insuficiência - e de avaliações sobre o papel político da política e os seus instrumentos de regulação. Manifesta-se o incômodo pelo distanciamento das instituições nacionais dos problemas individuais e coletivos da vida quotidiana $(4,31)$, comentário que se estende ao conjunto das instituições quando se afirma a incomodidade que produz a incapacidade das instituições em geral para enfrentar os efeitos produzidos pela globalização $(4,29)$, a alienação gerada pelo distanciamento das instituições européias dos problemas da vida quotidiana $(4,19)$ ou a lamentação pelo papel secundário do Estado nas decisões políticas $(3,96)$.

Mais do que uma retirada para uma subcultura política antisistema, encontramo-nos com os relevos estruturais de um espaço de construção política alternativa à globalização econômica e à plêiade de injustiças e desigualdades que se produz em distintos sectores sociais e âmbitos geográficos.

\section{Conclusões}

A caracterização social dos ativistas alterglobalização entrevistados aponta para algumas diferenças em relação às 
tradicionalmente atribuídas quer aos membros do movimento operário, quer aos dos novos movimentos sociais. Diantes destes, o seu perfil acentua mais a sua juventude, o seu maior nível de formação educativa, um maior contacto com as novas tecnologias da informação, uma presença mais acentuada de mulheres e uma menor exposição à precariedade laboral.

Tudo parece indicar que a velha categoria de "radicalismo de classe média" se está complementando com uma presença crescente de profissionais do conhecimento e pessoas habituadas ao manuseio de informação tanto de caráter geral como profissional. No entanto, resulta complicado apresentar uma conclusão muito mais elaborada que esta que aqui apresentamos, visto que uma parte significativa dos ativistas alterglobalização participam, por sua vez, nos que foram denominados novos movimentos sociais.

A multimilitância parece ser um aspecto frequiente entre os ativistas entrevistados, com uma reduzida presença de filiados em partidos políticos e organizações sindicais e uma massiva presença de ativistas de outros movimentos sociais, associações voluntárias e organizações não-governamentais. O seu ativismo encontra-se submetido a uma forte renovação e a uma colaboração limitada no tempo, com uma escassa presença daqueles que têm mais de cinco anos de antiguidade, embora a maioria mantenha uma participação habitual e representem uma percentagem muito reduzida os que apenas participam de forma pontual. Situados ideologicamente nas posições extremas da esquerda, declaram-se, na imensa maioria, não crentes e não praticantes em termos religiosos.

Uma minoria situa a sua identidade política no fato de pertencer a um movimento global (17\%) em face de uma maioria que se posiciona preferencialmente em outros tipos de movimentos $(83 \%)$. Significa isto que a maioria rejeita pertencer a um movimento global? É possível que ambos sentimentos de pertença se tornem compatíveis ou que se considere ser o mesmo? Apenas $11,4 \%$ rejeitam pertencer a um movimento global, 30,1\% afirma que a sua identidade política está vinculada à sua pertença ao movimento global e até $81,3 \%$ se sente parte constitutiva do referido movimento. Em termos de 
pertença, existe um território que possibilita compatibilizar a identificação política com um movimento setorial e a pertença a um movimento mais amplo.

Se Melucci tem razão quando afirma que a identidade coletiva é uma definição partilhada produzida tanto pela interação entre indivíduos que faz referência às orientações da sua ação, como pelas oportunidades e limites nos quais a dita ação tem lugar, encontramonos perante uma identidade coletiva com um perfil muito claro, preciso e amplamente estendido entre os entrevistados. Os ativistas parecem ter presente: a) que com a sua ação querem construir um movimento o mais amplo possível; b) que se mobilizam pessoalmente para oporse ao domínio econômico, para afirmar princípios morais de igualdade e justiça e para transformar as estruturas políticas e a democracia; c) que o interesse para se unirem a outros descansa na possibilidade de mudar uma realidade social não desejada, gerar solidariedade, construir com outros interesses comuns e partilhar das reivindicações; d) que o movimento alterglobalização é eficaz porque está contribuindo para a consciencialização dos riscos da globalização e para mudar a perspectiva sobre ela; e, e) que o que provoca maiores problemas de gestão em qualquer movimento (pluralismo, diversidade) parece ser o que mais atrai aos ativistas: pluralidade dos componentes, caráter horizontal e democrático do movimento e o fato de se referir a questões que transpõem as fronteiras culturais. Mas isto é possível? Podem coexistir, sem chegar a desintegrarem-se, componentes e perspectivas políticas assim tão díspares? Podem habitar num mesmo território?

A cartografia que desenham as respostas dos ativistas alterglobalização delineia um espaço tridimensional resultado da intersecção de dois planos: um, horizontal (dever ser), que indica o desejo de equiparação igualitária, desde o que é julgado o segundo, vertical (ser), que marca e denuncia as estruturas de desigualdade social e econômica (poder das multinacionais, ausência do conhecimento científico e tecnológico da resolução dos problemas sociais, ausência de equilíbrio ecológico, especulação e exploração econômica, concentração de poder e ausência de eqüidade). 
As avaliações dos ativistas alterglobalização estruturam um espaço social, um espaço, por sua vez, simbólico, uma cosmovisão que permite definir a globalização e os seus descontentes em torno de três eixos: o primeiro remete para o espacial, o segundo para o racional e o terceiro para as práticas que levam a cabo os distintos agentes participantes.

a) Dentro-fora, inclusão-exclusão como se pode verificar nos itens "falta de emprego", "conseqüências laborais da globalização", "acesso desigual ao consumo", "domínio exercido por quem controla a produção de informação" ou "ausência de equiidade entre os gêneros";

b) Acima-abaixo, imposição-repressão como corresponderia aos itens "incerteza da vida profissional", "políticas de privatização do ensino e da investigação", "sistema educativo demasiado ligado às necessidades do mercado e determinado por uma perspectiva neoliberal", "consumo de bens como símbolo de status", "falta de controle sobre aspectos importantes da tua vida", "falta de controle dos indivíduos sobre o modelo de sociedade", "repressão de estilos de vida alternativos", "excessiva concentração do poder", "imposição de modelos de liberdade individual" ou "falta de reconhecimento de diferenças culturais";

c) As práticas, agentes e instituições que configuram o espaço conflitual, "desempregados", "multinacionais e grupos financeiros", "cientistas e tecnólogos", "países em vias de desenvolvimento", "países desenvolvidos", "estilos de vida alternativos", "modelos de sociedade", "indústria cultural", "capital", "instituições nacionais", "Estados".

Tudo isto configura uma cosmovisão, mas também espaços de vida, espaços que são habitáveis ou que, pelo menos, pretendem tornar-se habitáveis a partir de outra maneira de entender a globalização e de práticas alterglobalizadoras.

A coincidência em torno do diagnóstico sobre a globalização que encontramos entre os ativistas alterglobalização não nos pode 
deixar indiferentes se tivermos em conta a grande diversidade constitutiva do seu suporte estrutural; sobretudo, porque a sua primeira identificação não se produz na maioria dos casos como membros de um movimento global, mas sim como atores de outros movimentos e formas organizativas. Ambos os elementos, a globalização ou alterglobalização e a sua multiplicidade de espaços de vida, por um lado, e a pluralidade estrutural como suporte material de um diagnóstico excessivamente coerente, por outro lado, colocam um paradoxo que não é possível elucidar aqui, mas que não resistimos em colocar: Como é possível que desde a fragmentação, a pluralidade e a diversidade de um "movimento de movimentos" se marque a pertença comum a um movimento global? É o movimento global constituído por uma série de manifestações homeomórficas (definições dotadas de proximidade e continuidade) ou é o "global" um significante vazio no qual todas as demandas são possíveis, um significante que torna possível a articulação de demandas muito diversas, uma espécie de ecumenismo reivindicativo?

\section{Notas}

1 Todos os entrevistados deviam cumprir duas condições: pertencer a alguma organização, associação ou movimento sociopolítico e ter participado pelo menos uma vez em alguma mobilização alterglobalização.

2 Dada a importância destes aspectos e o volume material procedente de entrevistas pessoais que possuímos, deixamos para um futuro desenvolvimento o aprofundamento nesta dimensão.

3 Não estaríamos totalmente de acordo com a afirmação de Polleta e Jasper de que a identidade coletiva é a percepção de partilhar de um mesmo status ou relação (ligações emocionais, cognitivas e morais com uma comunidade mais ampla) que é ou pode ser imaginada antes que diretamente experimentada. Existem multidões de testemunhos de ativistas que narram como experimentaram diretamente essas ligações com outros ativistas em momentos de mobilização ou ao levar a cabo ações multitudinárias de resistência ou oposição, e como o seu efeito perdurou na sua consciência durante muito tempo. 
4 O conceito de cartografia política reflete, em nossa opinião, de maneira mais precisa que, por exemplo, o da cultura política o que vamos desenvolver em seguida.

The movement for global justice in Spain: its activists, their political identity and the cartography of alter-globalisation

\begin{abstract}
The rapid expansion of the globalisation processes in recent decades has given rise to the emergence of forms of resistance to their consequences, as well as to processes of social mobilisation in favour of an alternative globalisation. The article that we are presenting includes part of the results of research into the movement for global justice in Spain. In it we deal with the material base of this movement, the characteristics of its activists, their political identity, their motivations and interests, the identity attributed to the action of the movement, as well as the political cartography sketched out by the evaluations of the alter-globalisation activists. Our aim is to analytically dissect the coordinates that frame this new form of subjectivity, whose social space is articulated around three axes: the spatial axis (inside-outside, inclusion-exclusion, centre-periphery), the relational axis (above-below, imposition-opposition, repressionliberation) and the axis of praxis (diversity of social practices carried out by the participating agents).
\end{abstract}

Key-words: social movements, collective action, political identity, forms of resistance to globalization

\title{
Referências bibliográficas
}

ALMOND, Gabriel A.; VERBA, Sidney. The civic culture. Boston: Little Brown, 1965.

ALONSO, Luis Enrique. Trabajo y postmodernidad: el empleo débil. Madrid: Fundamentos, 2000.

BARTH, Frederic. Los grupos étnicos y sus fronteras. México: FCE, 1976.

BELL, Allan; WEINBERGl, Martin. Homosexualities: a study of diversity among men and women. New York: Simon and Schuster, 1978.

BERGER, Peter; LUCKMANN, Thomas. The social construction of reality: a treatise in the Sociology of Knowledge. Harmondsworth: Penguin Books, 1967. 
BOURDIEU, Pierre. Razones prácticas: sobre la teoría de la acción. Barcelona: Anagrama, 1997.

CASTELLS, Manuel. La era de la información: Economía, Sociedad y Cultura: el fin del milenio. Madrid: Alianza, 1998. v. 3.

COHEN, Anthony P. The symbolic construction of community. London: Routledge, 1985.

CODOL, Jean-Paul. Une approche cognitive du sentiment d'identité. Information sur les sciences sociales, v. 20, n. 1, 1981.

DAHRENDORF, Ralf. El conflicto social moderno. Madrid: Mondadori, 1990.

DELLA PORTA, Donatella; DIANI, Mario. Social movements. Oxford: Blackwell, [1997], 1999.

DELLA PORTA, Donatella; TARROW, Sidney. Transnational protest \& global activism. Lanham: Rowman \& Littlefield, 2005.

DURKHEIM, Emile. Las formas elementales de la vida religiosa: el sistema totémico en Australia. Madrid: Akal, 1982.

EDER, Klaus. The new politics of class: social movements and cultural dynamics in advanced societies. Londres, Sage, 1993.

EISENSTADT, Samuel N. El Estado, la Sociedad y la formación de Centros: algunos problemas en la evolución de la Sociología Política. Revista Española de la Opinión Pública, n. 18, Oct.-Dic. 1969.

ERIKSON, Erik H. The concept of identity in race relations: notes and queries. Daedalus, n. 95, 1966.

GUIOT, Jean M. Attribution and identity construction: some comments. American Sociological Review, n. 42, Oct. 1977.

HABERMAS, Jürgen. Problemas de legitimación en el capitalismo tardío. Buenos Aires: Amorrortu, 1975.

INGLEHART, Ronald. El cambio cultural en las sociedades industriales avanzadas. Madrid: CIS-Siglo XXI, 1991.

KASTERSZTEIN, Joseph. Aspects psychosociaux de l'identité. Information sur les sciences sociales, v. 20, n. 1, 1981.

MARTÍNEZ DE ALBENIZ, Iñaki. La poética de la política: los usos de la política en el País Vasco. Bilbao: Servicio de Publicaciones de la Universidad del País Vasco, 2004. 
MELUCCI, Alberto. Getting involved: identity and mobilization in social movements. International Social Movement Research, n. 1, p. 329$348,1988$.

. Nomads of the present: social movements and individual needs in contemporary society. London: Hutchinson Radius, 1989.

. The process of collective identity. In: JOHNSTON, Hank; KLANDERMANS, Bert (Eds.). Social movements and culture. Londres: UCL Press, 1995. p. 41-63.

Challenging codes: collective action in the information age. Cambridge: Cambridge University Press, 1996.

McADAM, Doug. Political process and the development of black insurgency: 1930-1970. Chicago: The University of Chicago Press, 1982.

OFFE, Claus. Partidos políticos y nuevos movimientos sociales. Madrid: Sistema, 1988.

OMI, Michael; WINANT, Howard. By the rivers of Babylon: race in the United States, part II. Socialist Review, n. 72, p. 35-52, Nov./Dec. 1983.

PLUMMER, Ken. The making of the modern homosexual. Maryland: Rowman \& Littlefield, 1981.

POLLETTA, Francesca; JASPER, James M. Collective identity and social movements. Annual Review of Sociology, n. 27, p. 283-305, 2001.

SHILS, Edward A. Center and periphery. In: THE LOGIC of personal knowledge: essays presented to Michael Polanyi on his seventieth birthday, $11^{\text {th }}$ March 1961. London: Routledge \& Paul, 1961.

SMITH, Anthony D. National identity. London, Penguin, 1991.

TABOADA-LEONETTI, Isabelle. Identité individuelle, identité collective. Information sur les science sociales, v. 20, n. 1, 1981.

TAJFEL, Henri. Social identity and intergroup behaviour. Social science information, v. 13, n. 2, 1981.

TARROW, Sidney. Power in movement: social movements, collective action and politics. Cambridge: Cambridge University Press, 1994.

TAYLOR, Verta; WHITTIER, Nancy E. Collective identity in social movements communities: lesbian feminist mobilization. In: MORRIS, A.D.; MUELLER, C. M. (Eds.). Frontiers in social movement theory. New Haven: Yale University Press, 1992. p. 104-129. 
TEJERINA, Benjamín. El poder de los símbolos: identidad coletiva y movimiento etnolingüístico en el País Vasco. Revista Española de Investigaciones Sociológicas, n. 88, p. 75-105, Oct.-Dic. 1999b.

TEJERINA, B.; FERNANDEZ SOBRADO, J. M.; AIERDI, X. Sociedad civil, protesta y movimientos sociales en el País Vasco. Vitoria-Gasteiz: Servicio Central de Publicaciones el Gobierno Vasco, 1995.

TEJERINA, Benjamín; MARTÍNEZ DE ALBÉNIZ, Iñaki. Movimientos sociales y globalización en Euskal Herria. In: BERIAIN, J.; FERNÁNDEZ UBIETA, R. (Coords.). La cuestión vasca: claves de un conflicto cultural y político. Barcelona: Proyecto A, 1999c. p. 244-256.

WEBER, Max. La acción social: ensayos metodológicos. Barcelona: Península, 1984.

WEINER, Richard. Collective identity formation and social movements. Psychology and Social Theory, n. 3, spring-summer, 1982.

ZALD, Mayer N.; McCARTHY, John D. Social movements in an organizational society: collected essays. New Jersey: Transaction Publishers, 1987. 